\title{
Charge Remote Fragmentation of Fatty Acids Cationized with Alkaline Earth Metal Ions
}

\author{
Enrico Davoli \\ Laboratory of Environmental Pharmacology and Toxicology, Mario Negri Pharmacological Research Insti- \\ tute, Milan, Italy, and Midwest Center for Mass Spectrometry, Department of Chemistry, University of \\ Nebraska-I.incoln, I incoln, Nebraska, UJSA
}

\section{Michael L. Gross}

Midwest Center for Mass Spectromelry, Department of Chemistry, University of Nebraska-Lincoln, Lincoln, Nebraska, USA

\begin{abstract}
Fatty acids can be collisionally activated as $\left[\mathrm{M}-\mathrm{H}+\mathrm{Cat}^{+}\right.$, where Cat is an alkaline earth metal, by using tandem mass spectrometry. High-energy collisional activation induces charge remote fragmentation to give structural information. In the full scan mass spectra molecular ions are easily identified, particularly when barium is used as a cationizing agent; ions are shifted to a higher mass, lower chemical noise region of the mass spectrum. Moreover, the isotopic pattern of barium is characteristic, and the high mass defect of barium allows an easy separation of the cationized analyte from any remaining interfering ions (chemical noise), provided medium mass-resolving power is available. An additional advantage is that most of the ion current is localized in $[\mathrm{M}-\mathrm{H}+\text { Cat }]^{+}$species. Structural analysis of fatty acids can be performed when the sample size is as low as $1 \mathrm{ng}$. (J Am Soc Mass Spectrom 1990, 1, 320-324)
\end{abstract}

$\mathrm{T}$ The problem of locating double bonds and other functional groups in fatty acids and related materials is largely a solved problem in mass spectrometry. To overcome the difficulties with electron ionization (EI) mass spectrometry of simple fatty acid derivatives (e.g., methyl esters), a number of approaches have been designed to prevent isomerization or movement of the functional group and to enrich the sparse information content of the high-mass regions of EI spectra. These approaches were reviewed recently [1].

One approach, which we have promoted, makes use of charge remote fragmentations (CRFs) of closed shell ions [2-7]. The fragmentations effectively reveal the site of functional groups such as double bonds, multidouble bonds, branch points, cyclopropyl and cyclopropenyl rings, epoxides, and hydroxyl groups. They may be applied to steroids [8], surfactants [9], fatty alcohols [10], and prostaglandins (the latter subject is discussed in [11]), in addition to fatty acids. Moreover, the mechanisms of charge remote fragmentations are of some interest because they are a relatively new subject in ion chemistry $[3,10,12,13]$.

A key requirement for CRFs is a tightly localized charge site. Examples of such charge sites in fatty acids are carboxylate anions [2-6], cationized carboxylates (e.g., $[\mathrm{M}+\mathrm{Li}]^{+},[\mathrm{M}-\mathrm{H}+2 \mathrm{Li}]^{+}$) $[7]$, and protonated sites on derivative moieties having high pro-

Address reprint requests to Michael L. Gross, Department of Chemistry, University of Nebraska, Lincoln, NE 68588-0304. ton affinities [14]. A disadvantage of the carboxylate anions is that functional groups that stabilize an anionic site cause loss of $\mathrm{CO}_{2}$ in lieu of charge remote chemistry [4]. Cationization with alkali metal ions overcomes this problem, but this charge localization strategy works best with only the small metal jons (e.g., $\mathrm{Li}^{+}$and $\mathrm{Na}^{+}$) if CRFs are to be induced. Thus, there is a need to explore alternative approaches to localizing charge. Furthermore, other means of charge localization bring additional understanding and generality to the concept of CRF.

The new charge localization strategy reported in this and the accompanying paper [11] makes use of the interaction of alkaline earth metal ions with carboxylic acids to give $\left[\mathrm{M}-\mathrm{H}+\mathrm{Cat}^{+}\right.$, where Cat is $\mathrm{Mg}^{2+}, \mathrm{Ca}^{2+}, \mathrm{Sr}^{2+}$, or $\mathrm{Ba}^{2+}$. In this paper, we introduce the subject by examining the collision-activated dissociation (CAD) spectra of some typical fatty acids cationized with alkaline earth metals and by evaluating the detection limit. In the accompanying paper, the CAD spectra of barium-cationized prostaglandins are investigated as a means of obtaining structural information for this class of compounds.

\section{Experimental}

The studies were performed with a Kratos MS-50 Triple Analyzer of EBE design [15]. The first sector, MS-I, is a conventional Kratos MS-50 high resolution (EB) mass spectrometer. MS-II is a second electric sector. The instrument was equipped with a standard Kratos fast 
atom bombardment $(\mathrm{FAB})$ ion source and commercial saddle field FAB gun (Ion Tech, Middlesex, England) operated with argon at 6-8-keV translational energy and with a discharge current of approximately $2 \mathrm{~mA}$.

Cationization was accomplished by mixing on a copper probe tip the solid fatty acid with 3-nitrobenzyl alcohol (NBA) saturated with an appropriate alkaline earth metal hydroxide. Detection limit experiments were performed by adding a $500 \mathrm{pg} / \mu \mathrm{L}$ solution of the fatty acid to the matrix enriched with 5-10\% glycerol, all on a small area copper probe tip (area $=3 \mathrm{~mm}^{2}$ ). Glycerol permitted the signal to last longer, and the smaller tip allowed the concentration of the analyte to be increased in the matrix. We do not understand how the glycerol extended the sample signal.

Full scans of conventional mass spectra were performed with MS-I scanning at $\mathbf{2 0 0 0}$ resolving power and with MS-II fixed.

Collision-activated dissociation experiments were carried out with MS-I set at $\mathbf{3 0 0 0}$ mass resolution (peak width at $5 \%$ height), and mass-analyzed ion kinetic energy (MIKE) spectra were acquired by scanning MS-II. The 8-keV parent ions were activated by collisions with helium in the collision cell located in the third field-free region at the focal point of MS-I. The helium pressure was raised to accomplish a $30 \%$ reduction of the main beam. MS-II resolving power was limited to approximately 100 because of the kinetic energy release occurring during the fragmentation. MIKE spectra were the average of ten 20-second scans.

Fatty acids were purchased from Aldrich (Milwaukee, WI) and from Applied Science (State College, PA). 3-Nitrobenzyl alcohol was from Aldrich.

\section{Results and Discussion}

\section{Alkali Metal Cationization}

Cationization of organic molecules in mass spectrometry is a process that was first observed with field desorption [16]. The same reaction has been seen with other soft ionization techniques such as ${ }^{252} \mathrm{Cf}$ plasma desorption [17], laser desorption [18], secondary ion mass spectrometry [19], and FAB [20]. This kind of Lewis acid-base reaction (in which the metal cation is a Lewis acid) is thought to occur mainly at the liquid-solid interface under particle bombardment [21] or in "gaseous cavities" on the matrix surface, formed by a "phase explosion" $[22,23]$ caused by the bombarding atom.

From an analytical point of view, cationization in FAB is useful for determining molecular mass and for structural analysis [24]. The analyte cationization is in competition with the cationization of the matrix. Analyte cationization can be enhanced by choosing a matrix with a lower cation affinity or by selecting a cation with a higher affinity for the analyte.

Fast atom bombardment of the 3-NBA matrix saturated with $\mathrm{Ba}(\mathrm{OH})_{2}$ produces virtually no cationized 3-
NBA. The main ions are $(\mathrm{BaOH})^{+}(m / z 155)$, and protonated 3-NBA ( $m / z$ 154) and its dehydration product $(m / z 136)$. On the other hand, if this matrix is saturated with $\mathrm{LiOH}$, the most abundant ion is lithiated 3-NBA $(m / z 160)$, indicating that either 3-NBA has a lower affinity for barium than for lithium or the $\mathrm{Ba}^{2+}$ is more extensively solvated and adducts with NBA are desorbed with lower efficiency than $\mathrm{Li}^{+}$adducts.

Cationization of fatty acids in a FAB matrix saturated with alkali earth metal hydroxides results in the formation of $[\mathrm{M}-\mathrm{H}+\mathrm{Cat}]^{+}$ions. Moreover, if the cation is barium, the masses of all ions are shifted upward by $138 \mathrm{u}$ with respect to the free carboxylate into a region where chemical noise is lower. A comparison of full-scan mass spectra of an equimolar mixture of six different fatty acids desorbed from a 3-NBA matrix saturated with either $\mathrm{LiOH}$ or $\mathrm{Ba}(\mathrm{OH})_{2}$ was made. The fatty acids were (1) 10:0 (10 carbons, no unsaturation), (2) 16-OH, 16:0, (3) 18:0, (4) 9,10-epoxy, 18:0, (5) 18- $\mathrm{CH}_{3}, 19: 0$, and (6) trans-13, 22:1. Desorption from the $\mathrm{Li}^{+}$-containing matrix leads to production of both $[\mathrm{M}+\mathrm{Li}]^{+}$and $[\mathrm{M}-\mathrm{H}+2 \mathrm{Li}]^{+}$ions. Although the $[\mathrm{M}+\mathrm{Li}]^{+}$and $[\mathrm{M}-\mathrm{H}+2 \mathrm{Li}]^{+}$yields are of comparable abundance for each acid, these pairs of ions are most abundant for acid (4) and of approximately $20-30 \%$ for the others. The lowest mass ions, for $n$ decanoic acid, occur at $m / z 179$ and 185 , amid chemical noise from the matrix. Desorption from the $\mathrm{Ba}^{2+}$. containing matrix gives a single ion, $[\mathrm{M}-\mathrm{H}+\mathrm{Ba}]^{+}$. for each component. The relative responses of the various acids in both cases show some discrimination, and there is a relatively greater response for $n$-decanoic acid (1) and a correspondingly smaller response for (4) when desorbed as bariated species. The principal ion for $n$-decanoic acid is now scen at $m / z$ 309, well beyond the mass of any significant matrix ions. The presence of the barium-containing ions is readily recognized in the full-scan mass spectra by a characteristic isotope abundance pattern. (Barium is made up of one principal isotope, ${ }^{138} \mathrm{Ba}, 71.8 \%$, and minor amounts of ${ }^{134} \mathrm{Ba},{ }^{135} \mathrm{Ba}$, ${ }^{136} \mathrm{Ba}$, and ${ }^{137} \mathrm{Ba}$.)

\section{Collision-Activated Dissociation of Alkaline Earth Metal Cationized Fatty Acids}

Fast atom bombardment desorbed fatty acid [M$\mathrm{H}+\mathrm{Cat}]^{+}$ions undergo virtually no decompositions. In the metastable ion spectra, for example, no ions of appreciable abundance are detectable. High-energy collisional activation, however, produces a series of structurally informative ions.

For palmitic acid activated as $[\mathrm{M}-\mathrm{H}+\mathrm{Ca}]^{+}$, the charge remains associated with calcium-containing fragments, and no ions of a mass lower than $\mathrm{Ca}^{+} \cdot(\mathrm{m} / \mathrm{z}$ 40) are observed (see Figure 1). The pattern resulting from decomposition of a saturated fatty acid is mainly a series of closed shell (even electron) ions of approximately equal abundance, separated by $14 \mathrm{u}$, and belonging to the series $\left(\mathrm{CaO}_{2} \mathrm{CC}_{n} \mathrm{H}_{2 n}-{ }_{1}\right)^{+}$. The terminal 


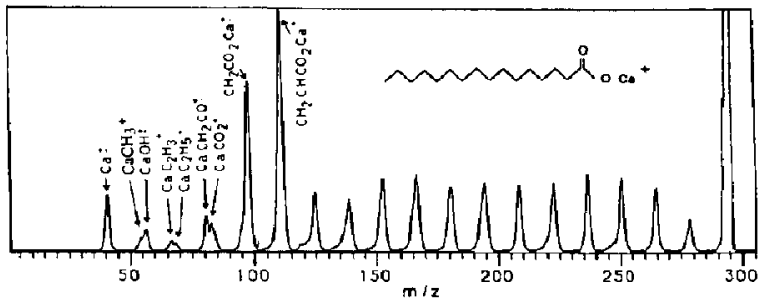

Figure 1. CAD MIKES of palmitic acid desorbed by FAB as a calcium cationized species.

ion in this series gives rise to the base peak, in this case a peak at $m / z 111$, corresponding to $\left(\mathrm{CaCO}_{2} \mathrm{C}_{2} \mathrm{H}_{3}\right)^{+}$. The likely reason for the high stability of this ion is that structures 1, 2, and 3 provide for charge delocalization. The series of fragments is consistent with that expected for CRP as has already been observed for fatty acids activated as $[\mathrm{M}-\mathrm{H}]^{-}$anions and as $[\mathrm{M}-\mathrm{H}+2 \mathrm{Li}]^{+}$ cations $[3,7]$.

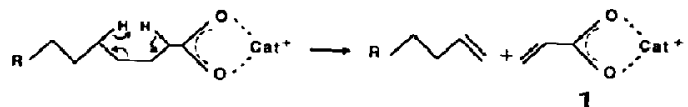<smiles>C=C[C@]12OC(=CCCC)O[C@@H](O1)O2</smiles>
2 3

In addition to the structurally informative closed shell ions, other even electron and radical cations are formed, as is indicated in the low-mass part of the spectra (see Figure 1). Their abundance pattern is similar for all the alkaline earth metal cationized fatty acids. The series starts with a radical cation of the metal and possibly some metal hydride, which, because of the low resolution of MS-II, is not resolved. At higher mass are unresolved doublets $\left(\mathrm{CaCH}_{3}\right)^{+}$ and $(\mathrm{CaOH})^{+}(m / z \quad 55$ and 57$),\left(\mathrm{CaCH}_{2} \mathrm{CO}\right)^{+}$. and $\left(\mathrm{CaCO}_{2}\right)^{+}(\mathrm{m} / \mathrm{z} 82$ and 84$)$, and the more abundant radical cation $\left(\mathrm{CaO}_{2} \mathrm{CCH}_{2}\right)^{+} \cdot(\mathrm{m} / z \mathrm{z})$. In the midst of these four peaks is another doublet, corresponding to $\left(\mathrm{CaC}_{2} \mathrm{H}_{3}\right)^{+}$and $\left(\mathrm{CaC}_{2} \mathrm{H}_{5}\right)^{+}(m / z 67$ and 69).

Collisional activation of unsaturated fatty acids desorbed as $[\mathrm{M}-\mathrm{H}+\mathrm{Cat}]^{+}$causes the expected CRFs as perturbed by the double bond. The spectral patterns are consistent with those of carboxylate anions and lithiated species (see Figure 2). One exception is the large relative abundance of $\left(\mathrm{CaO}_{3} \mathrm{CC}_{2} \mathrm{H}_{3}\right)^{+}(\mathrm{m} / \mathrm{z} 111)$, as is also found for the saturated acids when cationized with alkaline earth metal ions. A second exception is the apparent facile cleavages (with H-rearrangement) of the double bond and the vinyl bond for the [M $\mathbf{H}+\mathrm{MgJ}^{+}$ions (compare Figure $2 \mathrm{a}$ with $2 \mathrm{~b}-\mathrm{d}$ ). It is more likely that these ions are $\left[\mathrm{MgC}_{n} \mathrm{H}_{2 n}-{ }_{1}\right]^{+}$; for example, ions of the series $m / z 149,163,177,191$ may be $\left(\mathrm{C}_{9} \mathrm{H}_{17} \mathrm{Mg}\right)^{+},\left(\mathrm{C}_{10} \mathrm{H}_{19} \mathrm{Mg}\right)^{+},\left(\mathrm{C}_{11} \mathrm{H}_{21} \mathrm{Mg}\right)^{+}$, and $\left(\mathrm{C}_{12} \mathrm{H}_{23} \mathrm{Mg}\right)^{+}$, respectively. Peak broadening suggests that ions of adjoining masses are being produced. An
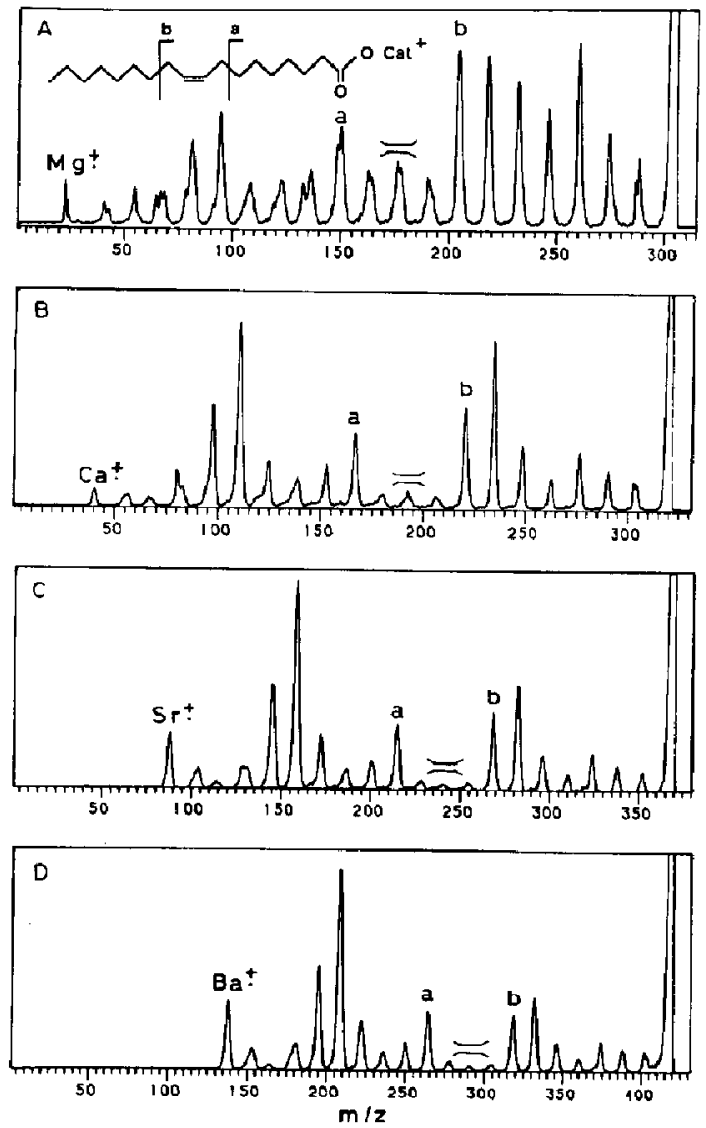

Figure 2. CAD MIKES of oleic acid desorbed by FAB as $[\mathrm{M}-\mathrm{H}+$ Cat $]^{+}$, where Cat is an alkaline earth metal: (a) magnesium, (b) calcium, (c) strontium, (d) barium. The ion formed by doublebond cleavage is indicated.

oxidative addition of $\mathrm{Mg}^{+}$with subsequent elimination of $\mathrm{C}_{n} \mathrm{H}_{2 n}$ and $\mathrm{CO}_{2}$ may account for the results.

For the other series cationized with alkaline earth metal ions, the CRFs are the dominant processes. The gap in the spectral pattern caused by the difficulty of cleaving vinyl and double bonds is reasserted and is as readily apparent as it is for carboxylates and lithiated species. Distinguishing isomers is straightforward, as can be seen by comparing the CAD spectrum of oleic acid (Figure 2d) with that of isomeric petroselenic acid (Figure 3).

Charge stabilization is sufficiently high to permit CRF of polyunsaturated fatty acids as evidenced by the CAD spectrum of arachidonic acid as $[\mathrm{M}-\mathrm{H}+\mathrm{Ba}]^{+}$. which shows that no isomerization of the double bonds occurs (see Figure 4). Polyunsaturated acid carboxylates show little charge remote chemistry, which is a limitation to their use in structural determinations [4]. The limitation is removed by turning to either alkali metal [7] or alkaline earth metal cationized species. 


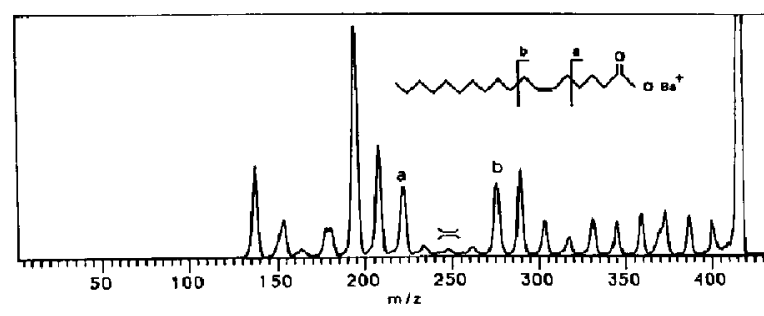

Figure 3. CAD MIKES of petroselenic acid desorbed by FAB as $[\mathrm{M}-\mathrm{H}+\mathrm{Ba}]^{+}$. The ion formed by double-bond cleavage is indicated.

\section{Detection Limit}

Fast atom bombardment mass spectrometry gives relatively poor sensitivity compared to EIMS. For example, it is usually not possible to obtain a useful full mass spectrum when sample quantities are in the low nanogram range. This is due to factors other than the sensitivity of the mass analyzer and detector. Factors such as the proton affinity of the analyte, the $\mathrm{pH}$ of the matrix, sample solubility, and surface activity greatly influence the quantity of desorbed ions. The major factor, however, is the signal-to-background ratio, which is degraded by the high chemical noise from matrixderived ions.

When fatty acids are desorbed as $[\mathrm{M}-\mathrm{H}+\mathrm{Ba}]^{+}$, three factors that influence the detection limit can be identified. First, as discussed carlier, the ions are shifted up in mass by $138 \mathrm{u}$ into a region where the chemical noise is lower. Second, the ion current is concentrated principally in $[\mathrm{M}-\mathrm{H}+\mathrm{Ba}]^{+}$. Third, because barium has a high mass defect, separating the cationized analyte from interfering ions of the same nominal mass is easily accomplished by using a mass resolving power of $\mathbf{3 0 0 0}$ for MS-I. For example, the signal for $[\mathrm{M}-\mathrm{H}+\mathrm{Ba}]^{+}$ions from $1 \mathrm{ng}$ of oleic acid $(m / z 419)$ at 3000 resolving power is compared with a scan in the absence of the analyte in Figure 5. This amount of sample produces a signal that is comparable to the height of the chemical noise but is well resolved from the major matrix ions at the same nominal mass. This signal is sufficiently long lived for six 20 -sec tandem mass spectrometry scans to be taken to confirm the structure of the responsible acid (Figure 6). It is emphasized that high selectivity is accomplished, and there

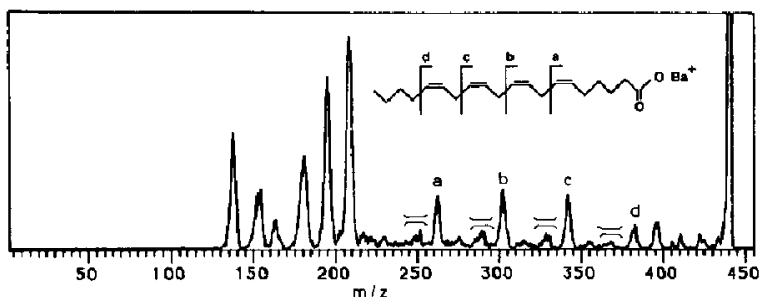

Figure 4. CAD MIKES of arachidonic acid desorbed by FAB as $[\mathrm{M}-\mathrm{H}+\mathrm{Ba}]^{+}$. The ions formed by double-bond cleavage are indicated.

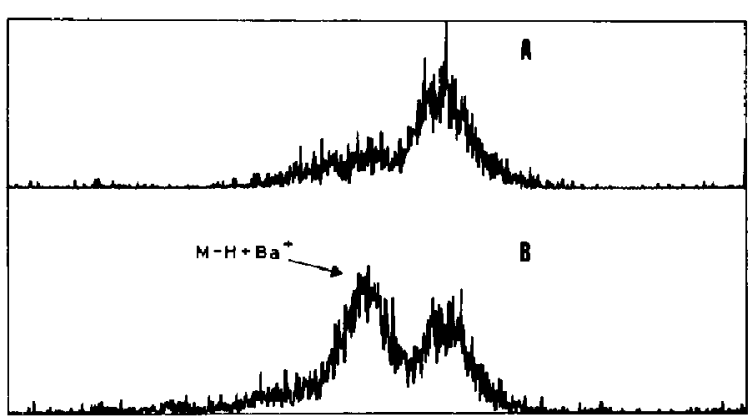

Figure 5. Narrow accelerating voltage scan over the nominal mass of $[M-H+B a]^{+}$of oleic acid: (a) blank matrix, (b) $1 \mathrm{ng}$ oleic acid. The matrix is $3-\mathrm{NB} A$ saturated with $\mathrm{Ba}(\mathrm{OH})_{2}$. Mass resolution is ca 3000 .

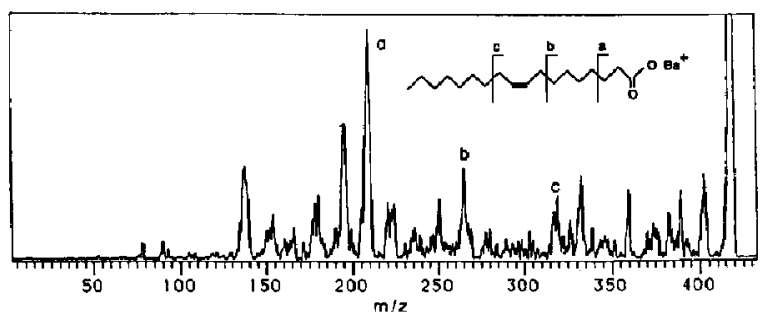

Figure 6. CAD MIKES scans of $1 \mathrm{ng}$ of oleic acid desorbed by FAB and activated as $[\mathrm{M}-\mathrm{H}+\mathrm{Ba}]^{+}$.

is only modest carryover from the chemical noise into the CAD spectrum of $1 \mathrm{ng}$ of oleic acid.

\section{Acknowledgment}

This research was supported by the Midwest Center for Mass Spectrometry, a National Science Foundation regional instrumentation facility (grant CHE-8620177).

\section{References}

1. Jensen, N.J.; Gross, M. L. Mass Spectrom. Rev. 1987, 6, 497.

2. Tomer, K. B.; Crow, F. W.; Gross, M. L. J. Am. Chem. Soc. 1983, 105, 5487.

3. Jensen, N. J.; Tomer, K. B.; Gross, M. L. J. Am. Chem. Soc. 1985, 107, 1863.

4. Jensen, N. J.; Tomer, K. B.; Gross, M. L. Anal. Chem. 1985, $57,2018$.

5. Jensen. N. J.; Gross, M. L. Lipids 1986, 21, 362.

6. Tomer, K. B.; Jensen, N. J.; Gross, M. L. Anal. Chem. 1986, $58,2429$.

7. Adams, J.; Gross, M. L. Anal. Chem. 1987, 59, 1576.

8. Tomer, K. B.; Gross, M. L. Biomed. Environ. Mass Spectrom. $1988,15,89$.

9. Lyon, P. A.; Stebbings, W. L.; Crow, F. W.; Tomer, K. B.; Lippstreu, D. L.; Gross, M. L. Anal. Chem. 1984, 56, 8. Lyon, P. A.; Crow, F. W.; Tomer, K. B.; Gross, M. L. Anal. Chem. 1984, 56, 2278.

10. Adams, J.; Gross, M. L. J. Am. Chem. Soc. 1986, $108,6915$.

11. Zirrolli, J. A.; Davoli, E.; Bettazzoli, L.; Gross, M.; Murphy, R. C. J. Am. Soc. Mass Spectrom. 1990, 1, 325-335. 
12. Adams, J.; Gross, M. L. J. Am. Chem. Soc. 1989, 111, 435.

13. Wysocki, V. H.; Bier, M. M.; Cooks, R. G. Org. Mass Spectrom. 1988, 23, 627.

14. Deterding, L. I.; Gross, M. L. Anal. Chim. Acta. 1987, 200, 431.

15. Gross, M. L.; Chess, E. K.; Lyon, P. A.; Crow, F. W.; Evans, S.; Tudge, H. Intl. J. Mass Spectrom. Ion Phys. 1982, 42, 243.

16. Heinen, H. I.; Giessmann, U.; Rollgen, F. W. Org. Mass Spectrom. 1977, 12, 710 .

17. Torgerson, D. F.; Skowronski, R. P.; Macfarlane, R. D. Biochem. Biophys. Res. Commun. 1974, 60, 616.

18. Posthumus, M. A.; Kistemaker, P. G.; Meuzelaar, H. L. C.;
Ten Noever de Braw, M. C, Anal. Chem, 1978, 50, 985.

19. Benninghoven, A.; Sichtermann, W. C. Anal. Chem. 1978, 50, 1181.

20. Barber, M.; Bordoli, R. S.; Elliot, G. J.; Sedgwick, R. D.; Tyler, A. N. Anal. Chem. 1982, 54, 645a.

21. Keough, T. Anal. Chem. 1985, 57, 2027.

22. Sunner, J.; Morales, A.; Kebarle, P. Anal. Chem. 1988, 60, 98.

23. Sunner, J.; Morales, A.; Kebarle, P. Abstracts of the 36th Conference on Mass Spectrometry and Allied Topics, San Francisco, 1988; p 944.

24. Pettit, G. R.; Holzapfel, C. W.; Cragg, G. M. J. Nat. Prod. 1984, 47, 941 . 